\title{
The axillary flap is a safer but tedious technique for Agger nasi cell removal compared to punch out procedures
}

\author{
Maysara A. Youssef ${ }^{\mathrm{a}}$, MSc;Ahmed A. Sadek ${ }^{\mathrm{a}}$, MD;and Moustafa Talaat, MD ${ }^{\mathrm{a}}$ \\ ${ }^{a}$ Otorhinolaryngology Dept., Faculty of Medicine, Minia University, Minia 61511, \\ Egypt.
}

\begin{abstract}
:
Objective:This study prospectively assessed the axillary flap approach versus punch-out procedure for agger nasi cell (ANC) removal.This is akey for successful frontal sinus surgery and its implication on the patency of the frontal ostium and middle turbinate lateralization(MTL).

Subjects and Methods: The study subjects consisted of 50 patients of whom 30 patients were males ( 80 frontal sinuses; 30 patients with bilateral disease and 20 patients with unilateral disease) with proven chronic frontal sinusitis, with pneumatized ANC according to CT findings.All patients undergone Endoscopic Sinus Surgery (ESS) with dissection of frontal recess. Group I included 40 sides that undergone removal of ANC using the axillary flap procedure (procedure 1), Group II included 40 sides that undergone removal of ANC using the punch out procedure (procedure 2). Adelaide chronic rhinosinusitis (CRS) symptom scoring questionnaires was used to all patients during their last follow-up visit 3 months after surgery.

Results: ANC were the most common variation and were observed in all the patients (20 patients unilaterally and 30 patients bilaterally). MTL following ANC removal has been found in 7.5\% ofGroup I and 25\% in Group II patients. Association between Adelaide symptoms severity score of postoperative symptoms and MTL was significant for nasal obstruction and rhinorrhea in both procedures (1 and 2). Non visualization of the frontal ostium following ANC removal has been found in $7.5 \%$ of Group I and $15 \%$ in Group II.Comparison between both procedures on MTL and non-visualization shows that the number of patients with MTL-positive using procedure 1 was significantly less than procedure 2 while there was a non-significant difference between procedure 1 and 2 regarding non-visualization.

Conclusions: The axillary flap technique is a safer procedure for resection of the ANC with perfect healing and less incidence of intraoperative and postoperative complications.However, it is a relatively difficult procedure and very time consuming while punch out procedure is a relatively easy, less time consuming procedure.
\end{abstract}

\section{INTRODUCTION}

The surgery in the frontal recess and on the frontal sinus remains a problem. This is because of the complex anatomy, the large anatomical variation of the frontal recess[18] and the location of the frontal recess behind the frontal beak[19].
The agger nasi cell (ANC) is the first cell seen in the coronal scan anterior to the insertion of the middle turbinate and is present in more than $90 \%$ of patients[2]. This cell forms the key to understanding the anatomy of the frontal recess as it can be easily identified on the computed tomography (CT) scan and 
in the patient during surgery[20]. The presence and pneumatization degree of the ANCaffect the anteroposterior dimension of the frontal sinus ostium and size of frontal beak [20]. The present study prospectively assessed the best technique for ANC removal using the axillary flap approach versus punch-out procedure as it is the key for a successful frontal sinus surgery and its implication on the patency of the frontal ostium and middle turbinate lateralization (MTL).

\section{SUBJECTS AND METHODS}

Thisis a prospective study conducted at the Department of Otorhinolaryngology, Minia University, Minia, Egypt, in the period from December 2015 to December 2016.The study subjects consisted of 50 patients (80 frontal sinuses) with chronic frontal sinusitis, with pneumatized ANC according to CT findings, who were prepared for Endoscopic Sinus Surgery (ESS). These patients were not responding to medical treatment in the presence of radiological and endoscopic evidence of chronic frontal sinusitis. All patients were subjected to complete pre-and postoperative means applied in ESS. Of these 50 patients, there was a male-tofemale ratio of 3:2 (30 male and 20 female patients), and a mean age of $\sim 29$ year.

All patients undergone ESS with dissection of frontal recess.Inclusion criteria consisted of all patients with frontal sinus pathology including chronic sinusitis, allergic polyposis and mucoceles with ANC presence confirmed by CT and undergoing ESS with dissection of frontal recess.Exclusion criteria includedpatients undergoing ESS without frontal recess dissection, patients below the age of 16 years, patients with malignant tumor involvement of frontal recess, frontal sinus, cases where ESS was abandoned due to excessive bleeding and patients who had previous ESS.The study subjects were prepared for ESS (80 procedures, 30 patients with bilateral disease and 20 patients with unilateral disease) was subdivided into two groups (Group I and Group II).Group I included40 sideswho undergone removal of ANC using the axillary flap procedure (procedure 1)and Group II included 40 sides undergone removal of ANC using the punch out procedure (procedure 2).Post-operative Adelaide chronic rhinosinusitis (CRS) symptom scoring questionnaires was used to all patients during their last follow-up visit after 3 months to assess the possibility of post-operative symptoms.

\section{Statistical Analysis:}

All statistical procedures were done using Statistical Package for Social Sciences (SPSS) computer software (version 24). Statistical significance is set at $\mathrm{P}<0.05$. To assess baseline characteristics, Fischer's exact test was used to test any unequal confounding effect of clinical variables between MTL-positive and MTL-negative patients. To test the association between postoperative symptoms (Adelaide symptoms severity score) and MTL, Chi square was used to test the significance between them in addition to Spearman correlation to assess existence of any correlation and its strength. In addition, Chi square test was used to compare between effects of procedure 1 and procedure 2 on MTL and nonvisualization and Cramer's correlation was used to assess if any correlation existed between them in addition to its strength. 


\section{Results}

Of the 50 patients, there was a male-to-female ratio of 3:2(30 malepatients of whom 20 hadbilateral diseaseand 10 hadunilateral disease and 20 female patients (10 with bilateral disease and 10 with unilateral disease). Gender distribution among both groups was as follow: Group I (40 sides) included 15 female patients and 25 male patients while Group II (40 sides) included 15 female patients and 25 male patients. The Mean age of both groups is shown in Table 1.

A summary of the patient symptoms, complications and the preoperative Lund and Mackay radiological score of the frontal sinuses is presented in Table 2. Twenty-six patients had chronic sinusitis in each group, four patients had allergic fungal sinusitisin group I, ten patients had allergic nasal polypi in each group and four patients had mucocele in group II. Four patients had preoperative complications one patient with intracranial and orbital complications having posterior table erosion with extension of the fronto-ethmoidal mucocele intracranially with erosion of the orbital roof and lamina papyracea with proptosis and blindness as shown in Fig. 1. Two patients had medial orbital wall erosion with extension of the mucocele into the orbit with proptosis and blindness of one of them and one patient with mucocele of the right ANC.

Concha bullosa of middle turbinate was observed in $20 \%$ of the study cases (10 patients): two patients on the right side, two patients on the left side and six patients on both sides, paradoxical middle turbinate was observed in eight (16\%) of the study cases: one patients on the right side, two patients on the left side and five patients on both sides. Haller's cell was observed in four (8\%) of the study cases: one patients on the right side, one patients on the left side and two patients on both sides. Pneumatization of crista galli was observed in four patients (8\%) of the study cases and deviated nasal septum (DNS) as anatomical variations was observed in $20(40 \%)$ of the study subjects:eight patients on the right side and twelve patients on the left side (Table 3).

Analysis of baseline characteristics revealed that there is non-significant effect regarding the confounding effect of clinical variables; chronic sinusitis, polyps, allergic fungal sinusitis and mucoceles between MTL-positive and MTL-negative subjects in both procedures $(1$ and 2$)$.The patients with bilateral disease were operated by both procedures one side with axillary flap procedure and the other side with punch out procedure. ANC were the most common variation and were observed in all the patients (20 patients unilaterally and 30 patients bilaterally).

Post-operative Adelaide CRS symptom scoring questionnaires was used to all patients during their last follow-up visit. This questionnaire includes questions on a five-point scale about the severity of five major CRS symptoms (nasal obstruction, rhinorrhea, postnasal drip, headache, and anosmia). The presence/absence of a symptom was determined according to the Adelaide symptom scoring systemwith a score of 1 meaning absence of the symptom(Table 4).

The postoperative status/anatomical location of the middle turbinate were recorded to assess lateralization. MTL was defined as any portion of the body or head of the MT contacting the lateral nasal wall. We,also, recorded whether the frontal sinus could be visualized, independent of MTL or not. MTL following ANC removal has been found in 7.5\% in Group I and 25\% in Group II.Association between Adelaide symptoms severity 
score of postoperative symptoms and MTL was significant for nasal obstruction and rhinorrhea in both procedures (1 and 2).

Visualization of frontal sinus recess and frontal sinus ostium was assessed by the ability to pass a $2.7 \mathrm{~mm}$ endoscope into the middle meatus to view these structures.Non visualization of the frontal ostium followingANC removal has been found in $7.5 \%$ of Group I and $15 \%$ in Group II.

We wanted to ascertain whether occurrence of MTL following surgery was associated with a poorer postoperative outcome or not. Comparison between the effect of procedure 1 and procedure 2 on MTL and non-visualization(Table 5) shows that the number of patients with MTL-positive using procedure 1 was significantly less than procedure 2 while there was a non-significant difference between procedure 1 and 2 regarding nonvisualization.

\section{Discussion}

We identifiedthe ANC in all the patients (30 patients bilaterally and 20 patients unilaterallywhich is coincident with onestudy[16]on 220 patients, where $100 \%$ of patients showed presence of ANC. In another study[13] on 192 patients, the prevalence of ANC was $89 \%$ and in a third study on 202 patients[11],it was $94.1 \%$, and $94 \%$ in a fourth study on57 patients[8].

In our study, it was observed that axillary flap technique is a very time consuming procedure and needs experience in contrary to a study performed by others[20]who stated that it is a relatively easy procedure.

In our study, MTL following ANC removal has been found in $7.5 \%$ of Group I and $25 \%$ of Group II.In another study, a lateralized middle turbinate was present in $78 \%$ of patients undergoing revision FESS[15].However, two other studies reported much lowerrates of postoperative middle turbinate lateralization,ranging from $22 \%$ to $36 \%[7,17]$. The rate of MTLwas approximately $15 \%$ in one study using axillary flap approach[6]and $25 \%$ in another study performed on 151 using axillary flap approach[1].

The association between MTL and postoperative symptoms as recorded on the Adelaide symptoms severity questionnaire was significant for nasal obstruction and rhinorrhea in both procedures while in another study[1], the association between MTL and postoperative symptoms was no significant using Kruskal-Wallis teston sixty-nine patients. The authors, then, tested for an association between MTL and the mere presence/absence of symptoms using univariate logistic regression models, and this also was not significant. Although they concluded that MTL is among the most common explanation for ESS failure and increase in the risk of revision surgery.

In order to prevent lateralization while preserving the MTs, numerous techniques have been described to encourage a medial position. One of the mostwidely recognized techniques is the controlled synechiatechnique(Bolgerization)[3], sut ure conchopexy (or medialization) of the MTs[9], metal clips to temporarily fix the MT to the septum[14] and middle meatal spacers[12].In our study, we adopted the bolgerazation technique.

In our study, non-visualization of the frontal ostium following ANC removal has been found in $7.5 \%$ of Group I and $15 \%$ in Group II. In one study on 64 
SOHAG MEDICAL JOURNAL The axillary flap is a safer but tedious technique for Agger nasi

patients (128 sides)using the axillary flap in removal of ANC, the nonvisualization of the frontal ostiumwas 4\%[19].Non-visualization was reported in $13 \%$ [4] while another report found $10 \%[10]$ and another study found $17.7 \%[5]$.

Results of association between Adelaide symptoms severity score of postoperative symptoms and nonvisualization, was significant for rhinorrhea, postnasal drip, headache/facial pain and anosmia in procedure 1 and for headache/facial pain and anosmia in procedure 2.Results of effect of procedure 1 and 2 on MTL showed thatthe number of patients with MTL-positive in procedure 1 was significantly less than procedure 2 , while there was no significant difference between procedure 1 and 2 regarding non-visualization.

\section{Conclusion}

The axillary flap technique is a safer procedure for resection of the ANC with perfect healing and less incidence of intraoperative (as insulting lamina papyracea) and postoperative complications (as MTL and adhesions). However, it is a relatively difficult procedure and very time consuming while punch out procedure is a relatively easy, less time consuming procedure. The punch out procedure carries risks of intraoperative complications (as insulting lamina papyracea) and postoperative adhesions and MTL. Therefore, the axillary flap technique is superior to punch out procedure in resection of ANC

Table (1): Baseline analysis of the study regarding gender and age distribution

(N=80)

\begin{tabular}{|l|c|c|}
\hline Variables regarding age and gender & group (1) & group (2) \\
\hline Gender (Count) & & 15 \\
Female & 15 & 25 \\
Male & 25 & 40 \\
Total & 40 & \\
\hline Age (Mean $\mathbf{n}$ SD) & & $31.7 \pm 11.7$ \\
Female & $29.1 \pm 8.1$ & $28.4 \pm 12.8$ \\
Male & $29.0 \pm 11.6$ & $29.7 \pm 12.4$ \\
Total & $29.0 \pm 10.3$ & \\
\hline
\end{tabular}

Table 2: Preoperative symptoms, complications and radiologic disease score for the frontal sinuses

\begin{tabular}{|l|c|c|c|c|c|}
\hline \multirow{2}{*}{ Disease process } & \multicolumn{2}{|c|}{ No. } & \multirow{2}{*}{$\begin{array}{c}\text { Pre-operative } \\
\text { Frontal Pain }\end{array}$} & $\begin{array}{c}\text { Pre-operative } \\
\text { complications }\end{array}$ & $\begin{array}{c}\text { Average Lund \& McKay } \\
\text { Score of frontal sinuses }\end{array}$ \\
\cline { 2 - 6 } & GI & GII & 52 & 0 & 1.3 \\
\hline Chronic Sinusitis & 26 & 26 & 10 & 0 & 2 \\
\hline Nasal Polyps & 10 & 0 & 3 & 0 & 1.98 \\
Allergic Fungal & 4 & 4 & 1 & $\begin{array}{c}\text { 1 orbital and } \\
\text { intracranial }\end{array}$ & 2 \\
\hline Mucoceles & 0 & 40 & 72 & 4 & 1.82 \\
\hline
\end{tabular}


SOHAG MEDICAL JOURNAL The axillary flap is a safer but tedious technique for Agger nasi Vol. 22 No. 2 July 2018 Ahmed A. Sadek

Table 3: Anatomical variations of sinonasal region of the 50 patients enrolled in the study

\begin{tabular}{|l|c|c|c|c|c|}
\hline & Right & Left & Both sides & Number & $\%$ \\
\hline Agger nasi & 10 & 10 & 30 & 50 & 100 \\
\hline Frontal cell Type 1 & 2 & 3 & 6 & 11 & 22 \\
Type 2 & 2 & 2 & 4 & 8 & 16 \\
Type 3 & 1 & 1 & 2 & 4 & 8 \\
Type 4 & 0 & 1 & 0 & 1 & 2 \\
\hline Concha bullosa & 2 & 2 & 6 & 10 & 16 \\
\hline Prominent Nasofrontal bony beak & 2 & 2 & 4 & 8 & 16 \\
\hline Paradoxical middle turbinate & 1 & 2 & 5 & 6 & 12 \\
\hline Haller"s cell & 1 & 1 & 4 & 4 & 8 \\
\hline Pneumatization of crista galli & 0 & 0 & 0 & 20 & 40 \\
\hline Deviated nasal septum & 8 & 12 & 0 & & $S Y M T O M$ \\
\hline
\end{tabular}

Table (4): POST-OPERATIVE SYMPTOMS ACCORDING TO ADELAIDE SYMPTOM SEVERITY SCORE GROUP I and II

\begin{tabular}{|c|c|c|c|c|c|c|c|c|c|c|c|c|}
\hline \multirow[t]{2}{*}{ POSTOPERATIVE SYMPTOM } & \multicolumn{5}{|c|}{$\begin{array}{l}\text { SCORE } \\
\text { Group I }\end{array}$} & \multirow{2}{*}{ TOTAL } & \multicolumn{5}{|c|}{$\begin{array}{l}\text { SCORE } \\
\text { Group II }\end{array}$} & \multirow{2}{*}{ TOTAL } \\
\hline & 1 & 2 & 3 & 4 & 5 & & 1 & 2 & 3 & 4 & 5 & \\
\hline NASAL OBSTRUCTION & 30 & 4 & 3 & 1 & 2 & 40 & 26 & 3 & 3 & 4 & 4 & 40 \\
\hline RHINORRHEA & 26 & 5 & 6 & 2 & 1 & 40 & 22 & 2 & 6 & 5 & 5 & 40 \\
\hline POSTNASAL DRIP & 26 & 5 & 6 & 2 & 1 & 40 & 22 & 2 & 6 & 5 & 5 & 40 \\
\hline HEADACHE/FACIALPAIN & 32 & 2 & 3 & 3 & 0 & 40 & 28 & 2 & 5 & 3 & 2 & 40 \\
\hline ANOSMIA & 37 & 2 & 1 & 0 & 0 & 40 & 37 & 2 & 1 & 0 & 0 & 40 \\
\hline
\end{tabular}

Table (5): Assessment of association between postoperative symptoms and MTL (N=80)

\begin{tabular}{|l|l|l|}
\hline Procedure 1 (N=40) & Chi square (P value) & $\begin{array}{l}\text { Spearman correlation (P value / } \\
\text { correlation coefficient } \mathrm{r})\end{array}$ \\
\hline Nasal obstruction & $<0.001^{* * *}$ & $<0.001 * * * / 0.60$ (moderate) \\
\hline Rhinorrhea & $<0.001^{* * *}$ & $0.02 * / 0.36$ (weak) \\
\hline Post nasal drip & 0.77 & $1.00 / 0.00$ (No) \\
\hline Headache/Facial pain & 0.66 & $0.36 / 0.15$ (very weak) \\
\hline Anosmia & 0.77 & $1.00 / 0.00$ (No) \\
\hline Procedure 2 (N=40) & Chi square (P value) & $\begin{array}{l}\text { Spearman correlation (P value / } \\
\text { correlation coefficient r) }\end{array}$ \\
\hline Nasal obstruction & $0.01^{*}$ & $0.002 * * / 0.48$ (moderate) \\
\hline Rhinorrhea & $0.006^{* *}$ & $0.02 * / 0.36$ (weak) \\
\hline Post nasal drip & 0.40 & $0.27 / 0.18$ (very weak) \\
\hline Headache/Facial pain & 0.51 & $0.27 / 0.18$ (very weak) \\
\hline & 0.40 & \\
\hline
\end{tabular}

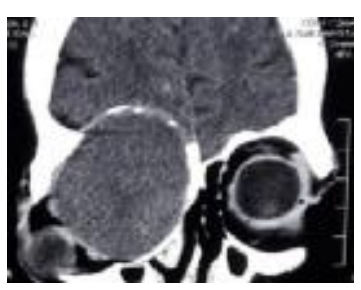


SOHAG MEDICAL JOURNAL The axillary flap is a safer but tedious technique for Agger nasi Vol. 22 No. 2 July 2018

Ahmed A. Sadek

Fig. 1. Fronto-ethmoidal mucocele with posterior table erosion, intracranial extension with

erosion of the orbital roof and lamina papyracea with proptosis and blindness.

\section{References}

1. Bassiouni A, Chen PG, Naidoo Y, Wormald PJ (2015) Clinical significance of middle turbinate lateralization after endoscopic sinus surgery. The Laryngoscope 125:36-41

2. Bolger WE, Parsons DS, Butzin CA (1991) Paranasal sinus bony anatomic variations and mucosal abnormalities: CT analysis for endoscopic sinus surgery. The Laryngoscope 101:56-64

3. Bolger WE, Kuhn FA, Kennedy DW (1999) Middle turbinate stabilization after functional endoscopic sinus surgery: the controlled synechiae technique. The Laryngoscope 109:18521853

4. Chan Y, Melroy CT, Kuhn CA, Kuhn FL, Daniel WT, Kuhn FA (2009) Long term frontal sinus patency after endoscopic frontal sinusotomy. The Laryngoscope 119:1229-1232

5. Chandra RK, Palmer JN, Tangsujarittham T, Kennedy DW (2004) Factors associated with failure of frontal sinusotomy in the early follow-up period. Otolaryngology-Head and Neck Surgery 131:514-518

6. Chen PG, Bassiouni A, Wormald PJ (2014) Incidence of middle turbinate lateralization after axillary flap approach to the frontal recess. In: International forum of allergy \& rhinology. Wiley Online Library, pp 333-338

7. Chiu AG, Vaughan WC (2004) Revision endoscopic frontal sinus surgery with surgical navigation. Otolaryngology-Head and Neck Surgery 130:312-318
8. Cho JH, Citardi MJ, Lee WT, Sautter NB, Lee H-M, Yoon J-H, Hong S-C, Kim JK (2006) Comparison of frontal pneumatization patterns between Koreans and Caucasians. Otolaryngology-Head and Neck Surgery 135:780-786

9. Dutton JM, Hinton MJ (2011) Middle turbinate suture conchopexy during endoscopic sinus surgery does not impair olfaction. American journal of rhinology \& allergy 25:125-127

10. Friedman M, Landsberg R, Schults RA, Tanyeri H, Caldarelli DD (2000) Frontal sinus surgery: endoscopic technique and preliminary results. American journal of rhinology 14:393404

11. Han D, Zhang L, Ge W, Tao J, Xian J, Zhou B (2008) Multiplanar computed tomographic analysis of the frontal recess region in Chinese subjects without frontal sinus disease symptoms. ORL 70:104-112

12. Lee JY, Lee SW (2007) Preventing lateral synechia formation after endoscopic sinus surgery with a silastic sheet. Archives of Otolaryngology-Head \& Neck Surgery 133:776-779

13. Lien CF, Weng $\mathrm{HH}$, Chang $\mathrm{YC}$, Lin YC, Wang WH (2010) Computed tomographic analysis of frontal recess anatomy and its effect on the development of frontal sinusitis. The Laryngoscope 120:2521-2527

14. Moukarzel N, Nehme A, Mansour S, Yammine FG, Moukheiber A (2000) Middle trubinate medialization 
SOHAG MEDICAL JOURNAL The axillary flap is a safer but tedious technique for Agger nasi Vol. 22 No. 2 July 2018 Ahmed A. Sadek

technique in functional endosocpic sinus surgery. Journal of OtolaryngologyHead \& Neck Surgery 29:144

15. Musy PY, Kountakis SE (2004) Anatomic findings in patients undergoing revision endoscopic sinus surgery. American journal of otolaryngology 25:418-422

16. Perez-Pinas I, Sabate J, Carmona A, Catalina-Herrera C, JimenezCastellanos J (2000) Anatomical variations in the human paranasal sinus region studied by CT. The Journal of Anatomy 197:221-227

17. Schaitkin B, May M, Shapiro A, Fucci M, Mester SJ (1993) Endoscopic sinus surgery: 4 year follow up on the first 100 patients. The Laryngoscope 103:1117-1120

18. Thawley SE, Deddens AE (1995) Transfrontal endoscopic management of frontal recess disease. American Journal of Rhinology 9:307-312

19. Wormald PJ (2002) The axillary flap approach to the frontal recess. The Laryngoscope 112:494-499

20. Wormald PJ, Xun Chan SZ (2003) Surgical techniques for the removal of frontal recess cells obstructing the frontal ostium. American journal of rhinology 17:221-226 